\title{
Surgical Denervation of Spermatic Cord for Chronic Scrotal Content Pain: A Modified Technique
}

\author{
Ehab M. Ahmed, MD, SBU and Ahmed J. Alsayyad, MD, FRCSC
}

Department Department of Urology, Faculty of Medicine

King Abdulaziz University, Jeddah, Saudi Arabia

\section{Correspondence}

Dr. Ahmed J. Alsayyad

P.O. Box 80215, Jeddah 21589, Saudi Arabia

e.M: aboassil@yahoo.com

Submission: 05 Jun. 2016

Accepted: $\quad 03$ Aug. 2016

\section{Citation}

Ahmed EM, Alsayyad AJ. Surgical denervation of spermatic cord for chronic scrotal content Pain: A modified technique. JKAU Med Sci 2016; 23 (4): 19-24. DOI: 10.4197/Med. 23.4.3

\begin{abstract}
Microsurgical denervation of the spermatic cord has been described as a treatment modality for patients with chronic scrotal content pain. The aim of our study is to evaluate a modified technique by performing denervation of the spermatic cord without a surgical microscope in patients with chronic scrotal content pain as a simplified modality. This retrospective study included 20 patients who underwent denervation of spermatic cord without using surgical microscope for treatment of intractable chronic scrotal content pain. Post denervation pain was assessed 6 months after the surgery. Twelve (60\%) patients reported complete alleviation of the symptoms, four (20\%) patients noticed more than 50\% improvement in their symptom, two (10\%) patients had less than $50 \%$ improvement, and two (10\%) patients reported no changes in their complaint. In conclusion, denervation of the spermatic cord without using surgical microscope is simple and feasible and shows comparable results to microsurgical denervation in treating patients with chronic scrotal content pain. Further studies are needed to confirm the efficacy of this modality.
\end{abstract}

\section{Keywords}

Chronic orchalgia; Chronic scrotal content pain; Denervation; Spermatic cord

\section{Introduction}

hronic scrotal content pain (CSCP) is defined as intermittent or constant pain in the testis for three months or longer which leads to significant interference with patient activities during the day so he would need to seek medical advice ${ }^{[1]}$. A survey among urologists in Switzerland in 2004, reported a mean of six new patients per month with CSCP who sought medical attention ${ }^{[2]}$. Patients with chronic scrotal pain represents a heterogeneous group due to variations in etiologies ${ }^{[1-20]}$. Potential causes for CSCP include vasectomy, inguinal hernia repair, spermatocele, varicocele, hydrocele, epididymitis, prostatitis, testicular tumor, intermittent torsion, radicular pain and referred pain from other origins ${ }^{[18,19]}$. However, up to $25 \%$ of CSCP have unknown etiology ${ }^{[1,20]}$. Chronic scrotal content pain is an uncommon problem but it affects up to 100,000 men per year due to different causes including $6 \%$ to $12 \%$ after vasectomy, up to $18 \%$ post inguinal hernia repair, up to $5 \%$ after different scrotal procedures and between $1 \%$ to $2 \%$ following abdominal or groin surgery ${ }^{[3-12]}$. Chronic scrotal pain is frustrating to many patients and most of them consult several physicians, undergo multiple diagnostic 
procedures including ultrasound and eventually CTscan, and are treated with repeated antibiotic courses and nonsteroidal anti-inflammatory drugs (NSAID), but usually with low success rates ${ }^{[13-16]}$.

Management of CSCP should always start with conservative medical therapy ${ }^{[21]}$. However, when less aggressive medical modalities fail, patients are often willing to undergo invasive surgeries, or even orchidectomy, for relief of their chronic pain ${ }^{[21]}$. Various surgical modalities exist including orchidectomy, epididymectomy, varicocelectomy, vasovasostomy, and microsurgical denervation of spermatic cord $(\mathrm{MDSC})^{[21]}$. Devine and Schellhammer initially described microsurgical denervation of the spermatic cord in two cases in $1978^{[22]}$ while Levine et al. described further details about this procedure in $1996^{[23]}$.

A major factor in CSCP development mechanism is altered nerve sensation around the spermatic cord $^{[24]}$. Ablating these altered nerve pathways in the cremasteric musculature, perivasal fascia, peri-arterial tissue and surrounding pericord lipomatous tissues is the cornerstone of MDSC to treat the pain ${ }^{[25,26]}$. Innervation of the scrotum arises from somatic nerves in the genital branch of the genitofemoral nerve, ilioinguinal nerves and autonomic branches from T10-L1 parasympathetic ganglia ${ }^{[27]}$. Wallerian degeneration (WD) is considered a potential cause of peripheral nerve hypersensitivity, although the exact mechanism of WD activation still controversial ${ }^{[24]}$.

We have applied a modified technique at our center by performing denervation of the spermatic cord without using a surgical microscope in patients with CSCP; aiming to evaluate the efficacy and safety of this simplified technique.

\section{Materials and Methods}

This is a retrospective study where a total of 20 patients underwent surgical denervation of spermatic cord for treatment of intractable chronic testicular pain. All patients reported either continuous or intermittent testicular pain for at least three months, which failed conservative medical treatment. The most common location of the pain was the upper pole of epididymis, or a soft tissue or lump just proximal to this region.

The patients underwent a full detailed medical history and physical examination to identify the possible location and etiology of pain. The medical history focused on previous genital infection, any previous surgeries in the groin, scrotum, pelvis and/or spine. Local trauma, other chronic pain conditions, analgesic use, psychiatric disorders and previous treatments were also assessed. Detailed evaluation was performed to identify the exact location of the pain (i.e.,testicle, epididymis, vas deferens or other cord structures), and to exclude other causes of pain such as chronic pelvic pain syndrome or pain due to urinary tract infections or structural or functional abnormalities. Duplex scrotal ultrasound was performed in all patients to rule out any abnormalities such as testicular tumor, torsion, varicocele, hydrocele, spermatocele, inguinal hernia or epididymo-orchitis. Preoperative spermatic cord block, which is recommended by several authors ${ }^{[21,22]}$, was used in only two patients to estimate the response of the surgery.

All patients received information about the risks of the procedure including failure to alleviate the pain, postoperative infection, bleeding, ischemia or even loss of the testis.

Follow up was conducted at six months after surgery. The pain outcomes after denervation were described as complete response, more than 50\% improvement, less than $50 \%$ improvement, or no response/deterioration.

\section{Procedure}

All the procedures were performed in the day-surgical unit with the patient under general anesthesia. Scrotal examination under anesthesia was performed to exclude any abnormality not identified in regular clinical examination. A $4 \mathrm{~cm}$ inguinal incision was made just above and parallel to the spermatic cord. The spermatic cord was dissected free and the vas deferens was dissected from surrounding soft tissues harboring the nerve fibers. In most cases, the testicular artery was successfully identified using intraoperative Doppler ultrasound probe. Once the artery was identified, soft structures between the vas deferens and the vessel sheath were divided. Afterwards, all the fibers of the cremasteric muscle, where the genital branch of the genitofemoral nerve runs, were sectioned and about four centimeters of the muscle was resected in order to minimize the risk of re-innervation. Coagulation of the muscle fibers was done meticulously to avoid postoperative bleeding. 


\section{Statistical Analysis}

Statistical analysis was performed using IBM SPSS Statistics for Windows, Release 21.0 (IBM Corp., Armonk, NY USA). Absolute frequencies, proportions and mean values were used to describe the data.

\section{Results}

Mean age was 46 years (ranging from 31 to 76 years). The mean duration of pain varied from 3-12 months. Eighteen patients underwent unilateral procedure, divided equally by the right and left sides and two patients underwent bilateral procedures. At 6-month post denervation, 12 (60\%) patients reported complete alleviation of the symptoms, four (20\%) patients noticed more than 50\% improvement in their symptom, two (10\%) patients had less than $50 \%$ improvement, and two (10\%) patients reported no changes in their complain (Table I). We did not encounter any significant intra-operative complication and all patients were discharged at the same day of surgery. However, scrotal hematoma developed in two (10\%) patients, and postoperative hydrocele was noticed in one $(5 \%)$ patient. None of these patients required another surgical intervention. In addition, no patient developed testicular ischemia or atrophy.

\section{Discussion}

Wallerian degeneration (WD) distribution was found in three main areas, including the cremasteric muscle, perivasal tissues and peri-arterial fascia ${ }^{[24]}$. The success of denervation procedures might be explained by ablation of the nerves in these areas ${ }^{[24]}$. It was suggested that more targeted denervation of these areas may lead to better success rate ${ }^{[24]}$. Particular attention to these areas during elective procedures, such as vasectomy and inguinal hernia repair, is suggested to avoid any irritation or trauma to the nerves and minimize the risk of future $\mathrm{CSCP}^{[24]}$. Chronic scrotal content pain is mediated by the scrotal and spermatic branches of the genitofemoral and ilioinguinal nerves, as well as by sympathetic fibers that supply the testis ${ }^{[14]}$.

Table 1. The outcome at six months after surgery.

\begin{tabular}{|l|c|}
\hline \multicolumn{1}{|c|}{ Post-operative Outcome } & N (\%) \\
\hline Complete Response & $12(60.00 \%)$ \\
\hline$>50 \%$ Improvement & $4(20.00 \%)$ \\
\hline$\leq 50 \%$ Improvement & $2(10.00 \%)$ \\
\hline No Change & $2(10.00 \%)$ \\
\hline N: Number of Patients & 20 \\
\hline
\end{tabular}

Microsurgical denervation of the spermatic cord may result in relief from CSCP by removing the afferent nerve stimulus ${ }^{[14]}$. The changes in the PNS and CNS can be down-regulated and the chronic pain stops ${ }^{[14]}$.

An exact cause for chronic scrotal or testicular pain is difficult to ascertain due to the inconsistent use of descriptors throughout the literature ${ }^{[17]}$. Around $25 \%$ of these patients never receive a satisfactory explanation for the exact etiology of their pain [20]. Many terms have been used to describe the chronic pain in the scrotum as testicular pain, chronic testicular pain, chronic scrotal pain, chronic orchalgia, chronic orchidynia, and chronic genital pain ${ }^{[17]}$. Chronic scrotal content pain, a term suggested by Levine 2010, to capture the phenomenon of chronic pain that occurs in different area of the genitalia including the testicle, testicular accessory structures, spermatic cord, epididymis, or the scrotal skin ${ }^{[17]}$. This term, however, fails to adequately determine the differences in innervation among these structures and may lead to difficult classification of this chronic pain syndrome ${ }^{[17]}$. A prospective study from a high volume vasectomy center in Oxford revealed that $15 \%$ of patients had some degree of scrotal discomfort up to 7 months postoperatively, somewhat overrepresented by the traditional instrumentation compared to Li's non-scalpel technique ${ }^{[28,29]}$. Out of these, $0.9 \%$ developed chronic testicular pain, which was severe and noticeably affected their quality of life ${ }^{[28,29]}$.

Nevertheless, when failure of conservative treatment is experienced in patients who suffer from chronic testicular pain, surgical treatment may be the only reasonable option ${ }^{[14]}$. Several radical surgical procedures such as inguinal or scrotal orchidectomy and epididymectomy have been used to manage CSCP with failure rates of up to $57 \% \%^{[1,13,30,31]}$. However, many studies show variable success rates in patients undergoing orchidectomy ${ }^{[21]}$. Davis et al. reported a success rate of $74 \%$ in a small series of 15 patients ${ }^{[1]}$. In addition, Yamamoto et al. ${ }^{[32]}$ shows 3 of 4 patients having complete success after orchidectomy. So, limited studies demonstrate success with orchidectomy in spite of the potential risk of psychological impact ${ }^{[21]}$. It should be regarded as the last option in patients with $\mathrm{CSCP}^{[21]}$. A recent long-term study, where 79 patients were operated on by MDSC with a mean follow-up of 20.3 months, revealed $71 \%$ of the surgeries were successful, $17 \%$ of patients experienced partial pain relief and $12 \%$ showed no pain relief ${ }^{[21]}$. Nowadays MDSC appears to be a reasonable approach to relieve 
the pain, preserve the testicle, stop chronic analgesic use, and resume daily living activities ${ }^{[21]}$.

In CSCP resulting from hernia repair, it would be appropriate to find the ileoinguinal nerve proximal to the operation field and divide it. In cases of post vasectomy $\mathrm{CSCP}$, chronic inflammation, swelling and even perforation of the epididymal duct on specimen after vasectomy have been noticed due to elevated pressure. However, epididymectomy might be an option in these cases.

Denervation of the spermatic cord without using surgical microscope is a modified modality used in our center to treat 20 men with CSCP. It demonstrated almost similar efficacy compared to microsurgical techniques ${ }^{[21]}$. At six months post-surgery, $60 \%$ of patients experienced complete alleviation of pain while $20 \%$ observed more than 50\% improvement. On the other hand, only $10 \%$ of patients had less than $50 \%$ improvement and 10\% reported no changes in their symptoms. Our efficacy results are in line with those achieved after MDSC ${ }^{[21]}$. In addition, our modified technique has proved to be safe with no significant intra-operative or post-operative complications. Mild post-operative complications requiring no interventional management were reported (scrotal hematoma [10\%] and hydrocele [5\%]). Our modified technique can be easily done in a day-surgical unit. It carries the same idea of removing the afferent nerve stimulus by sectioning the cremastric muscle fibers and the fibers around the vas deferens. Moreover, vas deferens is preserved during the surgery to prevent further formation of sperm granuloma, which might cause persistent postoperative pain.

Our study has some limitations including the retrospective design, limited number of patients, short follow-up period, and lack of using preoperative cord block in most patients. A larger scale long-term controlled study is required to further assess the outcomes of our modified technique.

\section{Conclusion}

Denervation of the spermatic cord without using surgical microscope is feasible and shows comparable results to microscopic denervation of the spermatic cord in treating patients with chronic scrotal content pain. Further studies are needed to confirm the efficacy of this modality.

\section{Conflict of Interest}

The authors have no conflict of interest.

\section{Disclosure}

The authors did not receive any type of commercial support either in forms of compensation or financial for this study. The author have no financial interest in any of the products or devices, or drugs mentioned in this article.

\section{Ethical Approval}

Obtained.

\section{References}

[1] Davis BE, Noble MJ, Weigel JW, Foret JD, Mebust WK. Analysis and management of chronic testicular pain. J Urol 1990; 143(5): 936-939.

[2] Strebel RT, Leippold T, Luginbuehl T, Muentener M, Praz $V$, Hauri D. Chronic scrotal pain syndrome: management among urologists in Switzerland. Eur Urol 2005; 47(6): 812816.

[3] Morris C, Mishra K, Kirkman R. A study to assess the prevalence of chronic testicular pain in post-vasectomy men compared to non-vasectomised men. J Family Planning Reprod Health Care 2002; 28(3): 142-144.

[4] Nangia AK, Myles JL, Thomas AJ. Vasectomy reversal for the post-vasectomy pain syndrome:: a clinical and histological evaluation. J Urol 2000; 164(6): 1939-1942.

[5] Myers SA, Mershon CE, Fuchs EF. Vasectomy reversal for treatment of the post-vasectomy pain syndrome. J Urol 1997; 157(2): 518-520.

[6] Chen T, Ball R. Epididymectomy for post-vasectomy pain: histological review. Br J Urol 1991; 68(4): 407-413.

[7] Dickinson K, Thomas M, Fawole A, Lyndon P, White C. Predicting chronic post-operative pain following laparoscopic inguinal hernia repair. Hernia 2008; 12(6): 597-601.

[8] Massaron S, Bona S, Fumagalli U, Battafarano F, Elmore U, Rosati R. Analysis of post-surgical pain after inguinal hernia repair: a prospective study of 1,440 operations. Hernia 2007; 11(6): 517-525.

[9] Loos M, Roumen $R$, Scheltinga M. Classifying postherniorrhaphy pain syndromes following elective inguinal hernia repair. World J Surg 2007; 31(9): 17601765.

[10] McLoughlin J, Kelley C. Study of the effectiveness of bupivicaine infiltration of the ilioinguinal nerve at the time of hernia repair for post-operative pain relief. Br J Clin Prac 1989; 43(8): 281-283. 
[11] McMahon A, Buckley J, Taylor A, Lloyd S, Deane R, Kirk D. Chronic testicular pain following vasectomy. $\mathrm{Br} J$ Urol 1992; 69(2): 188-191.

[12] Choe J, Kirkemo A. Questionnaire-based outcomes study of nononcological post-vasectomy complications. J Urol 1996; 155(4): 1284-1286

[13] Costabile RA, Hahn M, McLeod DG. Chronic orchialgia in the pain prone patient: the clinical perspective. J Urol 1991; 146(6): 1571-1574

[14] Oliveira RGd, Camara C, Alves JdMAF, Coelho RF, Lucon AM, Srougi M. Microsurgical testicular denervation for the treatment of chronic testicular pain initial results. Clinics 2009; 64(5).

[15] Heidenreich A, Olbert P, Engelmann UH. Management of chronic testalgia by microsurgical testicular denervation. Eur Urol 2002; 41(4): 392-397.

[16] Planken E, Voorham-van der Zalm PJ, Lycklama ANAA, Elzevier HW. Chronic testicular pain as a symptom of pelvic floor dysfunction. J Urol 2010; 183(1): 177-181.

[17] Quallich SA, Arslanian-Engoren C. Chronic testicular pain in adult men: an integrative literature review. Am J Men Health 2013; 7(5): 402-413.

[18] Keoghane SR, Sullivan ME. Investigating and managing chronic scrotal pain. BMJ (Clin Res) 2010; 341: c6716.

[19] Masarani M, Cox R. The aetiology, pathophysiology and management of chronic orchialgia. BJU Inter 2003; 91(5): 435-437.

[20] Ciftci H, Savas M, Gulum M, Yeni E, Verit A, Topal U. Evaluation of sexual function in men with orchialgia. Arch Sex Behav 2011;40(3): 631-634

[21] Strom KH, Levine LA. Microsurgical denervation of the spermatic cord for chronic orchialgia: long-term results from a single center. J Urol 2008; 180(3): 949-953.

[22] Devine Jr C, Schellhammer P. The use of microsurgical denervation of the spermatic cord for orchialgia. Transactions of the American Association of Genito-Urinary Surgeons. 1977; 70: 149-151.

[23] Levine LA, Matkov TG, Lubenow TR. Microsurgical denervation of the spermatic cord: a surgical alternative in the treatment of chronic orchialgia. J Urol 1996; 155(3): 1005-1007.

[24] Parekattil SJ, Gudeloglu A, Brahmbhatt JV, Priola KB, Vieweg J, Allan RW. Trifecta nerve complex: potential anatomical basis for microsurgical denervation of the spermatic cord for chronic orchialgia. J Urol 2013; 190(1): 265-270.

[25] Strom KH, Levine LA. Microsurgical denervation of the spermatic cord for chronic orchialgia: long-term results from a single center. J Urol 2008; 180(3): 949-953.

[26] Parekattil SJ, Gudeloglu A, Brahmbhatt J, Wharton J, Priola KB. Robotic assisted versus pure microsurgical vasectomy reversal: technique and prospective database control trial. J Reconstr Microsurg 2012; 28(7): 435-44.
[27] Kumar P, Mehta V, Nargund VH. [Clinical management of chronic testicular pain] Urologia Internationalis 2010; 84(2): 125

[28] Ahmed I, Rasheed S, White C, Shaikh NA. The incidence of post-vasectomy chronic testicular pain and the role of nerve stripping (denervation) of the spermatic cord in its management. Br J Urol 1997; 79(2): 269-270.

[29] LeslieTA, Illing RO, Cranston DW, Guillebaud J. The incidence of chronic scrotal pain after vasectomy: a prospective audit. BJU Int 2007; 100(6): 1330-1333.

[30] Padmore DE, Norman RW, Millard $\mathrm{OH}$. Analyses of indications for and outcomes of epididymectomy. J Urol 1996; 156(1): 95-96.

[31] West AF, Leung HY, Powell PH. Epididymectomy is an effective treatment for scrotal pain after vasectomy. BJU Int 2000; 85(9): 1097-1099.

[32] Yamamoto M, Hibi H, Katsuno S, Miyake K. Management of chronic orchialgia of unknown etiology. Intern J Urol 1995; 2(1): 47-49. 


\title{
الاستئصال الجراحي لأعصاب الحبل المنوي: طريقة جديدة لعلاج آلام الصفن المزئة
}

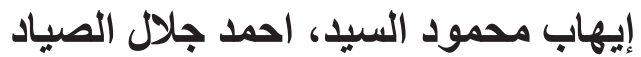

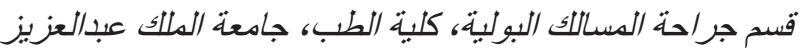 \\ جلة - مالمهلكة العربية السعودية
}

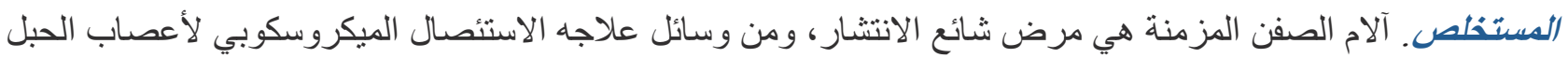

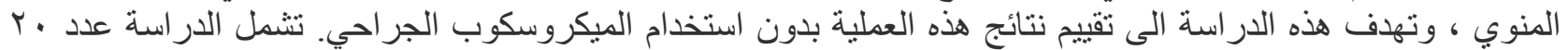

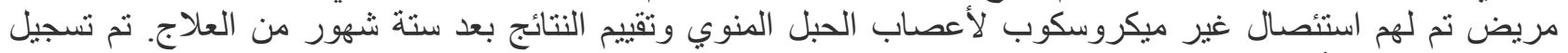

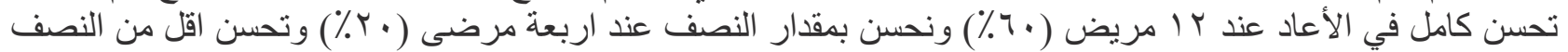

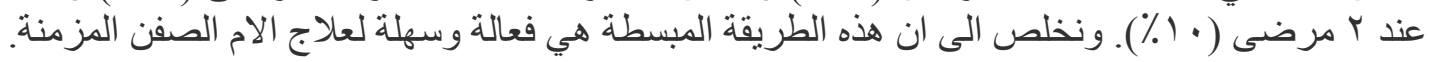

